santhemum [19]. Dwarf varieties easily fit the size of pot and looks adjusted from outside. The decorative and fluffy bloomed cultivars are ideal for garland making and hair decoration. The extra-large bloomed cultivars are prized for their display value. Though the flower yield and quality are primarily varietals characters, they are also greatly influenced by climatic factors. The successful cultivation of this plant is principally due to the great diversity of cultivars [20]. Different transform plants are grown in Bangladesh. A numerous number of chrysanthemum cultivars are found in Bangladesh. Jamal Uddin, et al. [21] observed that the 32 chrysanthemum cultivars coded from V1 to V32 were used for a study in Bangladesh. The cut blooms are also used in cemeteries in Japan [22]. Most of them are flowered in winter season. Genetic variation for flower yield and its component attributes were not properly studied in the past.

The leaves of this herb are edible and flowers have a pleasant smell. A condition for good quality cut flowers is that numerous flowers should be borne on long stems with healthy insect and disease -free foliage. It has ornamental value and many pharmaceutical firms dependent on several plants for medicine in the Western world. The pharmacopoeias have developed from ancient herbs. The leaf decoction is popularly used for the treatment of colds, headache, bronchitis, rheumatism, swellings and boils [23] as the leaf contents are enriched with anti-bacterial properties. Chrysanthemum is highly aromatic due to several volatile compounds of their essential oils, many of which are used in the flavor and fragrance purposes. The flower heads of $C$. indicum are sometimes used as chamomile adulterants. According to Jaime [24] the leaves are used for suppression of suspicious odors in foods such as soup, yuzu or pepper in Japan. It is available in tropical and subtropical zones [25] and widely distributed in the Mediterranean region, Japan, China and the Philippines [26]. The diploid and tetraploid taxa of the Chrysanthemum are distributed mainly in Mediterranean region and Europe [27]. The spatiosum variety used as Chinese vegetable and others part of the plant are also used for treating different diseases. The bark is purgative and also to treat syphilis. It is rummage-sale against constipation, stomach parasitic contagions and real in the fight against nematodes and protects plants against caterpillars. The extract of $C$. indicum showed strong and selective allelopathic activity [27]. The flowers are stomachic, insecticidal and well known for its use against skin allergies like hitch [28]. In spite of being a prospective crop, high occurrence of insect pests, and diseases are one of the main factors for the reduction of the yield and quality flower of $C$. indicum plant. Considering all these facts this study has been undertaken to certify the barriers and properties $C$. indicum crop plant. Keeping the threats of insect pests and diseases infestation of Chrysanthemums in a view point, this paper makes an attempt to assess the management techniques of the pests through different means that are feasible to adopt by the growers. The general objective is to assess the severe insect pests and diseases of the plants, extent of damages, and the management approaches. Also, the medicinal and esthetic significance of the plant has been highlighted.

\section{CHRYSANTHEMUM CULTIVAR}

Table 1 listed the popularly cultivated cultivars of Chrysanthemum in Bangladesh. Due to the favorable environmental conditions and an increased demand for flowers, a large number of different cultivars have high potential to be cultivated in dif-

Table 1. Different cultivars of Chrysanthemum in Bangladesh

\begin{tabular}{llll}
\hline \multicolumn{4}{c}{ Cultivars of Chrysanthemum } \\
\hline (1) Kanchil & (7) Sabdhawna & (13) Shukla & (19) Beauty \\
(2) Glumohr & (8) Flirt & (14) Puspa Anmol & (20) Jubilee \\
(3) Shayamal & (9) Neelima & (15) Yellow Bangla & (21) Maghi Orange \\
(4) Sadwin Yellow & (10) White prolific & (16) Sharad Mala & (22) Maghi White \\
(5) White Andaman & (11) Ravikiran & (17) Star white & (23) Kalvin Orange \\
(6) Aparjita & (12) Birbal Sahni & (18) Waters May & (24) Maghi yellow \\
\hline Source: Kumar et al. [29] & & & \\
\hline
\end{tabular}


ferent regions. Some of the cultivars are shown in Table 1.

\section{INSECT PESTS OF CHRYSANTHEMUM CROP}

The $C$. indicum plant is popular for possessing medicinal values however; its production is low due to the attack of a number of harmful sucking pests. Most cultivars are sensitive to aphids and infiltrations can lower quality and cause transmission of viruses' fiend out [30]. Visser, et al. [31] stated that a critical problem in chrysanthemum cultivation is outbreak of various insects such as aphids and others insect thrips (Frankliniella occidentalis Pergande) and spider mites (Tetranychus urticae Koch) on vegetative flowering and others parts of chrysanthemum. According to Teixeira da Silva, et al. [32] chrysanthemum is vulnerable to several insects and sucking pests which affect both the production and quality of the flowers at different growth stages. During the seedling stage, Spodoptera litura inhibits the growth of young plants. With growth of plants, infestation of sucking pests, mainly aphids, will be more. Chrysanthemum is affected by two aphids mainly chrysanthemum aphid and cotton aphid. Grasshoppers, thrips and spider mites are minor pests feeding on the plant specially flowers and leaves. The usually affect flower bud opening. The infestation continues even at full blooming stage. Aphids effect on these striking plants by sucking from the phloem of the vascular bundles of early shoots and leaves [33]. Plant parts affected by aphids will wilt, discolor or deform [34]. Aphids are regularly found in groups on plant tips, shoots of new growth or flowers. They multiply so fast on favorable conditions that a light infestation may increase to alarming proportions in a week. Some of the major aphids which severely infest $C$. indicum are briefly described below:

\subsection{Cotton aphid (Aphis gossypii Glover, 1877)}

The aphid is highly variable in color even within the same colony, ranging from light yellow to dark green, with dark Siphunculi and a pale or dusky. It is small to medium-sized, body length in apterous $1.05-1.90 \mathrm{~mm}$, in alate $1.05-1.77 \mathrm{~mm}$; This species is polyphagous and very threatening to many economically important plants [35] recorded this spe- cies infested Chrysanthemum sp. in Baghdad, the infection was linked with M. sanborni. A. gossypii as the most dominant species of chrysanthemum plant [34].

\subsection{Black bean aphid (Aphis fabae Scopoli, 1763)}

The aphid is dull greenish black to black. It is small to medium-sized, body length in apterous $1.60-2.25 \mathrm{~mm}$, in alate $1.80-2.6 \mathrm{~mm}$; originated on young leaves, stems and inflorescences of many plants, mainly Leguminosae, Chenopodiaceae and Compositae [36].

\subsection{Chrysanthemum aphid (Coloradoa rufomacu- lata Wilson, 1908)}

The green aphid is small, body length in apterous $1.0-1.5 \mathrm{~mm}$, in alate $0.9-1.5 \mathrm{~mm}$; sometimes with yellow spots at Siphunculi base; found on the stem and underside of leaves of Chrysanthemum sp. This aphid species was presented as a new record for Iraq aphid fauna [34].

\subsection{Chrysanthemum aphid (Macrosiphoneilla sanborni Gillette, 1908)}

The shiny, dark red-brown to blackish brown, broadly spindle shaped, with black, relatively short and thick is Siphunculi. It is small to medium sized, body length in apterous $1.40-2.20 \mathrm{~mm}$, in alate 1.40 $-2.30 \mathrm{~mm}$. The members of this species are found on young stems and bases of leaves of Chrysanthemum sp. [37] are the authors who noted this aphid species in Iraq on Chrysanthemum sp.

\subsection{Peach aphid (Myzus persicae Sulzer, 1776)}

The peach is whitish green, pale yellowish green, greyish green, mid-green or pink, rather uniformly colored, not shiny. It is small to medium-sized, body length in apterous $1.65-2.35 \mathrm{~mm}$, alate 1.90 $2.45 \mathrm{~mm}$, alate have a black central patch on the dorsal surface of the abdominal. According to Ali, et al. [34] the M. persicae is the lesser species in Chrysanthemum sp.

\subsection{Insect Pests Management}

In preliminary condition, it was observed that collection and destruction of the infested leaves, twigs, inflorescences and pod of the chrysanthemum crop that is mechanical control had good effects to manage the insect pests and the ladybird 
beetle, spider and damselfly as found good predators of aphid. Neem leaf extract @ 1 kg Neem leaves: 10 L water and Dimethoate40 EC @200 $\mathrm{mL}$ in $10 \mathrm{~L}$ water is suggested for one-acre land for controlling the aphid infestation. Botanical insecticides Neem leaf extract reduced the aphid population significantly on twigs, inflorescences and pods compared to untreated plants. In severe condition, application of insecticides was sprayed two times at seven days interval. Dimethoate 40EC, Carbosulfan 20 EC@2ml / L, Malathion-57 EC@0.2\% and imidacloprid200sl@0.25mL/L were used for controlling Aphid successfully [38].

\section{DISEASES OF CHRYSANTHEMUM CROP}

The chrysanthemum flower crop is sensitive to some diseases that decline the medicinal quality. The viruses belonging to the family Bunyaviridae, genus Tospo virus including tomato spotted wilt virus (TSWV) and impatiens necrotic spot virus (INSV) are very serious pathogens not only on chrysanthemum plants but also on other horticultural plants [39][40]. These viruses cause severe systemic necrosis on plants and a lethal effect in the worst cases. Moreover, these viruses are easily transmitted by a small insect to a wide range of plant species belonging to over 50 plant families. This causes difficulty in preventing commercial products from the infection by these pathogens.

According to Ikten, et al. [41] the C. indicum phytoplasma cell wall less bacteria is related with diseases in several hundred plant species. Viroid is the smallest infectious agent that causes serious diseases in vegetative propagated plant including chrysanthemum [42]. C. indicum stunt viroid (CSVd) is a serious pathogen in the chrysanthemum production industry, because it is easily transmitted mechanically during the course of propagation. The only effective approach to protect plants against its infection is to strictly monitor this pathogen. The CSVd infection causes symptoms such as decrease of plant height, which lowers the commercial value of cut flowers. There are three types of viruses of flower plant based on environment, ecology and phytosanitary consideration [43] and the first class includes viruses that have wide host ranges, usually have efficient vectors and already widespread in world wide.

\subsection{Virus}

Virus diseases in Chrysanthemum were not recognized prior to 1945. Chrysanthemum stunt was first reported to be a virus problem in 1947 [44]. By 1949 , it became a widespread and serious threat to the chrysanthemum field. The chrysanthemum stunt as a disease caused by a viroid (ChSV) [45]. By 1950 , other virus pathogens were discovered that caused problems in chrysanthemum production. Nowadays, virus has been seen to be a serious problem in chrysanthemum cultivation in agroecosystem in Bangladesh.

Roughing out of infested plants, destroy crop residues from the field and removable of the host plant can manage virus existence. Resistant variety should be used for healthy cultivation of chrysanthemum. Controlled of Aphid by using Malathion57 EC@0.2\% can be achieved to control insect vectors. Foliar spray of imidacloprid200@0.25 $\mathrm{mL} / \mathrm{L}$ of 7-11days interval can be practiced.

\subsection{Chrysanthemum rust}

The white rust (Puccinia horiana) was first recorded in Japan in 1895 and then noted in China and Japan until the 1960s. In present time, fungal disease of rust is a serious disease in flower crop. Today it is established in Asia, Europe, Africa, Australia, Central America, South America and the Far East. It can spread quickly in natural and nursery environments, causing huge crop losses and reduction the flower quality. Toguri, et al. [46] stated from recent study that improved an Agrobacterium mediated transformation system in chrysanthemum and obtained more than 80 transgenic lines with pacl and also investigated tolerance of transgenic chrysanthemum plants expressing Pacl protein against CSVd and TSWV.

Removal of susceptible volunteer chrysanthemum plants, barberry plants and avoid excess $\mathrm{N}$ fertilizer in the field is necessary. Early maturity cultivars help to minimize the rust disease in chrysanthemum plants. Spraying propiconazole $25 \%$ EC (a) $0.02 \%$ with $100 \mathrm{~L}$ water at 15 days interval of 2-3 times is effective to manage the rust in this plant.

\section{MEDICAL PROPERTIES OF CHRYSAN- THEMUM}

The chrysanthemum herb crop is a very im- 
Table 2. Diversified uses of chrysanthemum crop

\begin{tabular}{cl} 
No. & \multicolumn{1}{c}{ Health Benefits of Chrysanthemum } \\
1 & Encourage effective metabolism in the body, which can help people to lose weight, bettered circulation, \\
2 & Lower body temperature, and can help relieve the pain \\
3 & Detoxify the liver, making body healthier overall, as well as make cholesterol numbers lower \\
4 & Boost immune system because of its high level of Vitamin A and C \\
5 & Check chronic illness, prevents cellular mutations, and protects body against several illness caused by free \\
6 & Help alleviate varicose veins \\
7 & Rejuvenate the brain and alert the senses \\
8 & Help ease digestive issues with fewer stomach problems \\
9 & Improve bone density and prevent osteoporosis (due to presence of calcium and magnesium in plants) \\
10 & Improve eyesight by alleviating dryness and itchiness in eyes \\
11 & Treats cough and cold
\end{tabular}

portant medicinal plant and the whole plant parts are used for disease treatment. Many researchers investigated that the stems, leaves, and flowers of the plants are used as traditional medicine to treat vertigo, hypertensive symptoms, and several infectious diseases like pneumonia, colitis, stomatitis, carbuncle and fever [47]. Yet, systematic manipulation of these natural medicines for human health aids has not been carried out to a significant degree. In recent years, these basils have been the focus of care due to their medicinal and pharmacological values [48]. Plant products are widely used in pharmaceuticals, cosmetics and food trades. Many pharmaceutical companies in the Western world are contingent on many plants for their medicinal things. Pharmacopoeias have industrialized from ancient sages [49]. The extract of $C$. indicum the flowers were a flavone glucoside, acacetin 7-0-(3-0acetyl-ß-D-glucopyr-anoside) [50], has been isolated together with twenty-seven known compounds including flavonoids, caffeoylquinic acid derivatives, phenolics, and a monoterpenoid glucoside.

The medicinal plant native to China and Japan is Chrysanthemum indicum L. Its infusion is a remedy for intermittent fever, hysteria, and monthly irregularities. It is also used as carminative, tonic sedative, and for hypertension. Leaf decoction is a remedy for colds, headache, bronchitis, rheumatism, swellings and boils. The flower part is used as herbal medicine with strong aroma and many previous studies focused on its essential oil [13][51]-[53] which is prescribed for anti-inflammatory, analge- sic, antipyretic purposes, quercetin, myricetin and the treatment of eye disease in Chinese traditional preparations. It demonstrated inhibitory action against rat lens aldose reductase and nitric oxide production in lipopolysaccharide activated macrophages. It has been used as the antioxidant, antiinflammatory, anti-mutagenic, antimicrobial, antifungal, antiangiogenic, anti-atherosclerosis and nematocidal properties and the leaves are used as expectorant, bitter, and stomachic for the animal [54]. Hosni, et al. [55] observed that the volatile oil of wild chrysanthemums covers 22 components and the optimal extraction process is ethanol for 3 times, which can be achieved by adding $70 \%$ ethanol for 12 times. Some experts in the field of medicine have examined the pharmacological effect and chemical arrangement extraction methods of wild chrysanthemums medicinal herbs. Through the diagnosis of the claim in the clinical disease treatment, it can start that wild chrysanthemums have obvious pharmacological effect in clinical diseases and has certain application value. Xanthine oxidase (XO) is a key enzyme that catalyzes the oxidation of xanthine and hypoxanthine into uric acid [56], and plays a vital role in producing hyperuricemia and gout. Allopurinol is a clinically used XO inhibitor in the treatment of gout, which lumps the terminal step in uric acid biosynthesis and lowers the plasma uric acid concentration [57]. However, due to unwanted side effects of allopurinol, such as hepatitis, nephropathy, and allergic reactions, the search for new substitutes with increased therapeu- 
tic activity and fewer side effects are necessary. In addition, superoxide anion radicals caused by XO are involved in various pathological states such as hepatitis, inflammation, ischemia reperfusion, carcinogenesis, and aging [58]. Thus, the search for novel XO inhibitors would be helpful not only to treat gout but also to combat numerous other diseases.

The $C$. indicum is one of the popular traditional medicines extensively used in Vietnam and indigenous to China. The flowers are used under the name "Cuc Hoa Trang" for the treatment of fever, rheumatism, inflammation, headache, and eyesight disorder [59]. Nguyen, et al. [60] had performed a study on these plants. In the course of their screening program for XO inhibitory medicinal plants from Vietnam, they screened 288 extracts, prepared from 96 medicinal plants used in Vietnamese traditional medicine to treat gout and related symptoms. Among them, the $\mathrm{MeOH}$ extract of the flowers of C. indicum showed the most potent $\mathrm{XO}$ inhibitory activity with an IC50 value of $5.1 \mathrm{ug} / \mathrm{mL}$ [60]. Therefore, they carried out activity shown fractionation of the $\mathrm{MeOH}$ extract and isolated a newfangled flavone glucoside, together with 14 known flavonoids, seven caffeoylquinic acid derivatives, five simple phenolics, and a monoterpenoid glucoside.

The $C$. indicum flowers have been prescribed for anti-inflammation, analgesic, and antipyretic purposes and the treatment of eye disease in Chinese traditional preparations. In the course of our characterization studies on the bioactive constituents from medicinal foodstuffs [60][61] and medicinal flowers [62] reported the isolation and structural elucidation of three eudesmane-type sesquiterpenes, kikkanols A, B, and C, and five germacrene-type sesquiterpenes, kikkanols D, D monoacetate, E, F, and $F$ monoacetate, from the methanolic extract of the flowers of C. indicum cultivated in China [62]. In addition, the methanolic extract and several constituents were found to show inhibitory activities against rat lens aldose reductase10) and nitric oxide (NO) production in lipopolysaccharide (LPS)activated mouse peritoneal macrophages [63].

\section{PROBLEMS FACED IN CHRYSANTHE- MUM PRODUCTION}

Changes are occurring throughout farming sector today, and these changes could majorly affect pest management. Pesticides are extensively used in plant cultivation. When compared to other types of controlling methods, pesticides can provide instantaneous pest knock-down impact with limited control, but rarely a long-lasting solution to the problems. Due to huge marketing approaches of the agrochemical companies, many farmers have grown accustomed to applying pesticides, often as preventive solution against disease injuries and crop loss. Chrysanthemum disease management faces everincreasing problems due to: (i) rising demands for alternative plantations to support the burgeoning global population; (ii) declining production potential in agriculture because of more competition for land in fertile areas and exhaustion of marginal arable lands; (iii) worsening ecology of agroecosystems and depletion of natural resources; and (iv) increased hazard of disease epidemics resulting from agricultural intensification and monocultures. Fungicide resistance is an increasing menace to farmers. Most of the farmers lack sound knowledge on use of pesticides and other methods of disease control. Recommendations of the plant experts for use of appropriate dose of pesticides and fertilizers are not usually followed by the farmers. The problems lie in the lack of governmental and nongovernmental support to develop the effective agricultural policies, integrated pest management approaches, and the best way of pest and disease control.

\section{CONCLUSIONS}

As an ornamental and medicinal purpose, it is authoritative to recognize the bio active combinations which are responsible for its pharmacological effects especially in the essential oil as medicine of human body of the plant but its production hamper due to attack of a number of aphids as insect, virus as diseases and planting material as verities. The production of Chrysanthemum earmark problem is its cutting collection as well as its quality planting material's availability. The insects and diseases resistance cultivar and simultaneously integrated pest management approaches are inevitable for successful cut flower production of $C$. indicum. 
AUTHOR INFORMATION

\section{Corresponding Author}

Ahasan Ullah Khan - Department of Entomology, Sylhet Agricultural University, Sylhet-3100 (Bangladesh); Climate-Smart Agriculture Lab, Sylhet Agricultural University, Sylhet-3100 (Bangladesh);

(1) https://orcid.org/0000-0002-7029-8215

Email: ahasanullahsau@gmail.com

\section{Authors}

Md Abdur Razzak Choudhury - Department of Entomology, Sylhet Agricultural University, Sylhet-3100 (Bangladesh);

Anayat Ullah Khan - Department of Mathematics, Jashore University of Science and Technology, Jashore-7408 (Bangladesh);

Saugat Khanal - Department of Agriculture, Agriculture and Forestry University, Bharatpur44200 (Nepal);

(1) https://orcid.org/0000-0002-9146-7428

Abu Rashed Md Maukeeb - Department of Agricultural Chemistry, Khulna Agricultural University, Khulna-9208 (Bangladesh);

\section{ACKNOWLEDGEMENT}

This work was supported by the parents of the authors, colleagues, and the related field expert's professors. The authors owe their sincere gratitude to the all helping hands that assisted during manuscript preparation.

\section{REFERENCES}

[1] J. Chen, X. Yang, B. Li, K. Yang, Y. Wang, K. Sun, Y. Zhang, and W. Zhu. (2019). "A New Sesquiterpenoid from Chrysanthemum indicum". Chemistry of Natural Compounds. 55 (6): 1076-1079. 10.1007/s10600-01902898-y.

[2] M. C. Song, H. J. Yang, T. S. Jeong, K. T. Kim, and N. I. Baek. (2008). "Heterocyclic compounds from Chrysanthemum coronarium L. and their inhibitory activity on hACAT -1, hACAT-2, and LDL-oxidation". Archives of Pharmacal Research. 31 (5): 573-578. 10.1007/s12272-001-1195-4.
[3] J. H. Kang and J. S. Kim. (2020). "New diploid populations of chrysanthemum indicum 1. (asteraceae) from korea". Korean Journal of Plant Taxonomy. 50 (1): 17-21. 10.11110/ kjpt.2020.50.1.17.

[4] J. Vijayakumari, V. S. Prabha, E. J. Rayan, T. L. S. Raj, and S. B. Antony. (2019). "Floristic Diversity Assessment of Home Garden in Palayamkottai Region of Tirunelveli District, Tamil Nadu a Means of Sustainable Biodiversity Conservation". International Journal of Trend in Scientific Research and Development. 3 (3): 1484-1491. 10.31142/ijtsrd23390.

[5] J. Spaargaren and G. van Geest. (2018). in "Van Huylenbroeck J (ed) Ornamental Crops". Springer, Cham.

[6] C. Q. Sun, F. Di Chen, N. J. Teng, Z. L. Liu, W. M. Fang, and X. L. Hou. (2010). "Factors affecting seed set in the crosses between Dendranthema grandiflorum (Ramat.) Kitamura and its wild species". Euphytica. 171 (2): 181-192. 10.1007/s10681-009-0005$\underline{6}$.

[7] C. Q. Sun, F. Di Chen, N. J. Teng, Z. L. Liu, W. M. Fang, and X. L. Hou. (2010). "Interspecific hybrids between Chrysanthemum grandiflorum (Ramat.) Kitamura and C. indicum (L.) Des Moul. and their drought tolerance evaluation". Euphytica. 174 (1): 51 -60. 10.1007/s10681-009-0117-Z.

[8] C. Q. Sun, Z. Z. Huang, Y. L. Wang, F. D. Chen, N. J. Teng, W. M. Fang, and Z. L. Liu. (2011). "Overcoming pre-fertilization barriers in the wide cross between Chrysanthemum grandiflorum (Ramat.) Kitamura and C. nankingense (Nakai) Tzvel. by using special pollination techniques". Euphytica. 178 (2): 195-202. 10.1007/s10681-010-0297-6.

[9] M. Zhang, H. Huang, Q. Wang, and S. Dai. (2018). "Cross breeding new cultivars of early-flowering multiflora chrysanthemum based on mathematical analysis". HortScience. 53 (4): 421-426. 10.21273/ HORTSCI12769-17.

[10] A. Shafaghat, O. Ghorban-Dadras, M. Mohammadhosseini, M. Akhavan, M. Shafaghatlonbar, and A. Panahi. (2017). "A comparative Study on Chemical Composition 
and Antimicrobial Activity of Essential Oils from Tanacetum parthenium (L.) Schultz. Bip. and Tanacetum punctatum (Desr.) Grierson. Leaves from Iran". Journal of Essential Oil-Bearing Plants. 20 (4): 1143-1150. 10.1080/0972060X.2017.1383859.

[11] M. B. Hassanpouraghdam, S. J. Tabatabaie, H. Nazemiyeh, and A. Aflatuni. (2008). "N and $\mathrm{K}$ nutrition levels affect growth and essential oil content of costmary (Tanacetum balsamita L.)". Journal of Food, Agriculture and Environment. 6 (2): 150-154.

[12] B. Nickavar, G. Amin, and N. Mehregan. (2003). "Quercetine, a Major Flavonol Aglycon from Tanacetum balsamita L.". Iranian Journal of Pharmaceutical Research. 2 (4): 249-250. 10.22037/ijpr.2010.65.

[13] L. Y. Wu, H. Z. Gao, X. L. Wang, J. H. Ye, J. L. Lu, and Y. R. Liang. (2010). "Analysis of chemical composition of Chrysanthemum indicum flowers by GC/MS and HPLC". Journal of Medicinal Plants Research. 4 (5): 421-426.

[14] M. Yoshikawa, T. Morikawa, T. Murakami, I. Toguchida, S. Harima, and H. Matsuda. (1999). "Medicinal flowers. I. Aldose reductase inhibitors and three new eudesmane-type sesquiterpenes, kikkanols A, B, and C, from the flowers of Chrysanthemum indicum L". Chemical and Pharmaceutical Bulletin. 47 (3): 340-345. 10.1248/cpb.47.340.

[15] M. Yoshikawa, T. Morikawa, I. Toguchida, S. Harima, and H. Matsuda. (2000). "Medicinal flowers. II. Inhibitors of nitric oxide production and absolute stereostructures of five new germacrane-type sesquiterpenes, kikkanols D, D monoacetate, E, F, and F monoacetate from the flowers of Chrysanthemum indicum L.". Chemical and Pharmaceutical Bulletin. 48 (5): 651-656. 10.1248/ cpb.48.651.

[16] M. Dutt, M. Patil, and P. Sonawane. (2002). "Effect of various substrates on growth and flowering of chrysanthemum". Indian Journal of Horticulture. 59 (2): 191-195.

[17] S. M. Sharifuzzaman, K. A. Ara, M. H. Rahman, K. Kabir, and M. B. Talukdar. (2011). "Effect of GA3, CCC and $\mathrm{MH}$ on vegetative growth and yield of chrysanthemum". Inter- national Journal of Experimental Agriculture. 2 (1): 17-20.

[18] C. R. Adkar-Purushothama, G. Chennappa, K. P. Rao, M. Y. Sreenivasa, P. K. Maheshwar, M. N. N. Prasad, and T. Sano. (2017). "Molecular diversity among viroids infecting chrysanthemum in India". Virus Genes. 53 (4): 636-642. 10.1007/s11262-017 -1468-5.

[19] T. Thakur and H. S. Grewal. (2019). "Influence of potting media compositions on flower production of chrysanthemum (Chrysanthemum morifolium Ramat) cultivar Kikiobiory". Journal of Plant Nutrition. 42 (15): 1861-1867. 10.1080/01904167.2019.1648670.

[20] J. G. Barbosa. (2003). "Crisântemos: produção de mudas, cultivo para corte de flor, cultivo em vaso e cultivo hidropônico". Aprenda Fácil, Viçosa.

[21] A. F. M. J. Uddin, T. Taufique, A. F. Ona, S. Shahrin, and H. Mehraj. (2015). "Growth and flowering performance evaluation of thirty two chrysanthemum cultivars". Journal of Bioscience and Agriculture Research. 4 (1): 40-51. 10.18801/jbar.040115.41.

[22] A. J. Uddin, M. Islam, H. Mehraj, M. Roni, and S. Shahrin. (2013). "An Evaluation of Some Japanese Lisianthus (Eustoma grandiflorum) Varieties Grown in Bangladesh". The Agriculturists. 11 (1): 56-60. 10.3329/ agric.v11i1.15243.

[23] I. Sile, E. Romane, S. Reinsone, B. Maurina, D. Tirzite, and M. Dambrova. (2020). "Medicinal plants and their uses recorded in the Archives of Latvian Folklore from the 19th century". Journal of Ethnopharmacology. 249. 10.1016/j.jep.2019.112378.

[24] J. A. Teixeira Da Silva. (2004). "Mining the essential oils of the Anthemideae". African Journal of Biotechnology. 3 (12): 706-720. 10.5897/AJB2004.000-2134.

[25] A. Prakash and J. Rao. (2018). "Botanical pesticides in agriculture". Botanical Pesticides in Agriculture. 1-461. 10.1201/9781315138572.

[26] S. K. Bardaweel, M. M. Hudaib, K. A. Tawaha, and R. M. Bashatwah. (2015). "Studies on the in vitro antiproliferative, antimicrobi- 
al, antioxidant, and acetylcholinesterase inhibition activities associated with chrysanthemum coronarium essential oil". Evidencebased Complementary and Alternative Medicine. 2015. 10.1155/2015/790838.

[27] T. Lograda, M. Ramdani, P. Chalard, G. Figueredo, H. Silini, and M. Kenoufi. (2013). "Chemical composition, antibacterial activity and chromosome number of algerian populations of two chrysanthemum species". Journal of Applied Pharmaceutical Science. 3 (8). 10.7324/JAPS.2013.38.S2.

[28] A. Basu, S. K. Basu, R. Sengupta, M. Asif, X. Li, Y. Li, A. Hirani, P. Zandi, M. Sajad, F. Solorio-Sánchez, A. O. Mbuya, W. Cetzal-Ix, S. Tashi, T. Jongthap, D. Dhungyel, and M. Ahmad. (2017). in "Benkeblia N (ed) Phytonutritional Improvement of Crops". Wiley Blackwell, London.

[29] G. Kumar, K. Pal Singh, K. V. Prasad, M. K. Rana, Namita, and S. Panwar. (2014). "Genetic diversity analysis of chrysanthemum (Chrysanthemum grandiflorum) cultivars using RAPD markers," Indian Journal of Agricultural Sciences. 84 (11): 1323-1328.

[30] M. Valizadeh, C. Deraison, S. K. Kazemitabar, Y. Rahbé, and Maarten A Jongsma. (2013). "Aphid Resistance in Florist's Chrysanthemum (Chrysanthemum morifolium Ramat.) Induced by Sea Anemone Equistatin Overexpression". African Journal of Biotechnology. 12 (50): 6922-6930. 10.5897/ AJB2013.12956.

[31] P. B. Visser, R. A. de Maagd, and M. A. Jongsma. (2007). in "Pua E and Davey M (ed) Transgenic Crops VI". Springer, Berlin Heidelberg.

[32] J. A. Teixeira da Silva, H. Shinoyama, R. Aida, Y. Matsushita, S. K. Raj, and F. Chen. (2013). "Chrysanthemum Biotechnology: Quo vadis?". Critical Reviews in Plant Sciences. $\quad 32 \quad$ (1): $21-52$. 10.1080/07352689.2012.696461.

[33] M. Kutyniok and C. Müller. (2013). "Plantmediated interactions between shoot-feeding aphids and root-feeding nematodes depend on nitrate fertilization". Oecologia. 173 (4): 1367-1377. 10.1007/s00442-013-2712-x.

[34] H. B. Ali. (2017). "Seasonal population abundance of the Chrysanthemum aphids (Homoptera, Aphididae) in the middle of Iraq with pictorial key to species". Bulletin of the Iraq Natural History Museum. 14 (4): 315328. 10.26842/binhm.7.2017.14.4.0315.

[35] B. Hayder, B. K. Agarwala, and I. K. Kaddou. (2012). "New records of aphids of the Subfamily Aphidinae (Homoptera: Aphididae) infested herbaceous plants and shrubs for Iraqi aphid fauna". Advances in Bioresearch. 3 (4): 66-75.

[36] R. Blackman and V. Eastop. (2007). "Aphids on the World's Herbaceous Plants and Shrubs: An Identification Guide". Wiley Blackwell, London.

[37] F. S. Bodenheimer and E. Swirski. (1957). "The Aphidoidea of the Middle East". Weizmann Sci. Pr, Israel.

[38] M. A. Altieri and C. I. Nicholls. (2003). "Soil fertility management and insect pests: Harmonizing soil and plant health in agroecosystems". Soil and Tillage Research. 72 (2): 203 $-211.10 .1016 / \mathrm{S} 0167-1987(03) 00089-8$.

[39] P. Narayanasamy and P. Narayanasamy. (2011). "Detection of Virus and Viroid Pathogens in Plants". Microbial Plant PathogensDetection and Disease Diagnosis. 7-220. 10.1007/978-90-481-9754-5 2.

[40] Z. He, J. F. Guo, S. R. Reitz, Z. R. Lei, and S. Y. Wu. (2020). "A global invasion by the thrip, Frankliniella occidentalis: Current virus vector status and its management". Insect Science. 27 (4): 626-645. 10.1111/17447917.12721.

[41] C. Ikten, M. Catal, E. Yol, R. Ustun, S. Furat, C. Toker, and B. Uzun. (2014). "Molecular identification, characterization and transmission of phytoplasmas associated with sesame phyllody in Turkey". European Journal of Plant Pathology. 139 (1): 217-229. $10.1007 /$ s10658-014-0384-y.

[42] W. K. Cho, Y. Jo, K. M. Jo, and K. H. Kim. (2013). "A current overview of two viroids that infect chrysanthemums: Chrysanthemum stunt viroid and Chrysanthemum chlorotic mottle viroid". Viruses. 5 (4): 1099-1113. 10.3390/v5041099.

[43] N. W. Schaad, R. D. Frederick, J. Shaw, W. L. Schneider, R. Hickson, M. D. Petrillo, and 
D. G. Luster. (2003). "Advances in molecular -based diagnostics in meeting crop biosecurity and phytosanitary issues". Annual Review of Phytopathology. 41 : 305-324. 10.1146/ annurev.phyto.41.052002.095435.

[44] Y. Matsushita and M. Osaka. (2019). "Screening of Chrysanthemum seticuspe accessions reveals different degrees of resistance to chrysanthemum stunt viroid". European Journal of Plant Pathology. 154 (4): 1059-1066. 10.1007/s10658-019-01726-x.

[45] Y. Jo, H. Chu, H. Kim, J. K. Cho, S. Lian, H. Choi, S. M. Kim, S. L. Kim, B. C. Lee, and W. K. Cho. (2017). "Comprehensive analysis of genomic variation of Hop stunt viroid". European Journal of Plant Pathology. 148 (1): 119-127. 10.1007/s10658-016-1075-7.

[46] T. Toguri, T. Ogawa, M. Yoshioka, M. Kakitani, and M. Tukahara. (2003). "Agrobacterium-mediated Transformation of Chrysanthemum (Dendranthema grandiflora) Plants with a Disease Resistance Gene (pac1)". Plant Biotechnology. 20 (2): 121127. 10.5511/plantbiotechnology.20.121.

[47] A. E. Al-Snafi. (2018). "Traditional uses of Iraqi medicinal plants". IOSR Journal Of Pharmacy. 8 (8): 32-95.

[48] M. Li, P. W. Pare, J. Zhang, T. Kang, Z. Zhang, D. Yang, K. Wang, and H. Xing. (2018). "Antioxidant capacity connection with phenolic and flavonoid content in Chinese medicinal herbs". Records of Natural Products. 12 (3): 239-250. 10.25135/ rnp.24.17.08.138.

[49] C. Godswill. (2019). "Medicinal Plants: the Medical, Food, and Nutritional Biochemistry and Uses". International Journal of $\mathrm{Ad}$ vanced Academic Research | Sciences. 5 (11): 2488-9849.

[50] Y. Shao, Y. Sun, D. Li, and Y. Chen. (2020). "Chrysanthemum indicum L.: A Comprehensive Review of its Botany, Phytochemistry and Pharmacology". American Journal of Chinese Medicine. 48 (4): 871-897. 10.1142/ S0192415X20500421.

[51] S. Shen, Y. Sha, C. Deng, X. Zhang, D. Fu, and J. Chen. (2004). "Quality assessment of Flos Chrysanthemi Indici from different growing areas in China by solid-phase micro- extraction-gas chromatography-mass spectrometry". Journal of Chromatography A. $1047 \quad$ (2): 281-287. 10.1016/ j.chroma.2004.06.129.

[52] Q. Ye and C. Deng. (2009). "Determination of camphor and borneol in Flos Chrysanthemi Indici by UAE and GC-FID". Journal of Chromatographic Science. 47 (4): 287-290. 10.1093/chromsci/47.4.287.

[53] C. L. Jing, R. H. Huang, Y. Su, Y. Q. Li, and C. S. Zhang. (2019). "Variation in chemical composition and biological activities of flos chrysanthemi indici essential oil under different extraction methods". Biomolecules. 9 (10). 10.3390/biom9100518.

[54] A. R. Han, B. Nam, B. R. Kim, K. C. Lee, B. S. Song, S. H. Kim, J. B. Kim, and C. H. Jin. (2019). "Phytochemical composition and antioxidant activities of two different color chrysanthemum flower teas". Molecules. 24 (2). 10.3390/molecules 24020329 .

[55] K. Hosni, I. Hassen, H. Sebei, and H. Casabianca. (2013). "Secondary metabolites from Chrysanthemum coronarium (Garland) flowerheads: Chemical composition and biological activities". Industrial Crops and Products. 44 : 263-271. 10.1016/ j.indcrop.2012.11.033.

[56] Y. Si, J. W. Park, S. Jung, G. S. Hwang, E. Goh, and H. J. Lee. (2018). "Layer-by-layer electrochemical biosensors configuring xanthine oxidase and carbon nanotubes/graphene complexes for hypoxanthine and uric acid in human serum solutions". Biosensors and Bioelectronics. 121 : 265-271. 10.1016/ j.bios.2018.08.074.

[57] A. Šmelcerović, K. Tomović, Ž. Šmelcerović, Ž. Petronijević, G. Kocić, T. Tomašič, Ž. Jakopin, and M. Anderluh. (2017). "Xanthine oxidase inhibitors beyond allopurinol and febuxostat; an overview and selection of potential leads based on in silico calculated physico-chemical properties, predicted pharmacokinetics and toxicity". European Journal of Medicinal Chemistry. 135, : 491516. 10.1016/j.ejmech.2017.04.031.

[58] J. Qi, L. Q. Sun, S. Y. Qian, and B. Y. Yu. (2017). "A novel multi-hyphenated analytical method to simultaneously determine xanthine 
oxidase inhibitors and superoxide anion scavengers in natural products". Analytica Chimica Acta. 984 : 124-133. 10.1016/ j.aca.2017.07.023.

[59] N. T. Duong, P. D. Vinh, P. T. Thuong, N. T. Hoai, L. N. Thanh, T. T. Bach, N. H. Nam, and N. H. Anh. (2017). "Xanthine oxidase inhibitors from Archidendron clypearia (Jack.) I.C. Nielsen: Results from systematic screening of Vietnamese medicinal plants". Asian Pacific Journal of Tropical Medicine. 10 (6): 549-556. 10.1016/ j.apjtm.2017.06.002.

[60] M. T. T. Nguyen, S. Awale, Y. Tezuka, Q. Le Tran, H. Watanabe, and S. Kadota. (2004). "Xanthine oxidase inhibitory activity of Vietnamese medicinal plants," Biological and Pharmaceutical Bulletin. 27 (9): 1414 1421. 10.1248/bpb.27.1414.

[61] T. Murakami, A. Emoto, H. Matsuda, and M. Yoshikawa. (2001). "Medicinal Foodstuffs. XXI. Structures of New Cucurbitane-Type Triterpene Glycosides, Goyaglycosides-a, -b, -c, -d, -e, -f, -g, and -h, and New OleananeType Triterpene Saponins, Goyasaponins I, II, and III, from the Fresh Fruit of Japanese Momordica chara". Chemical \& Pharmaceutical Bulletin. 49 (1): 54-63. 10.1248/ cpb.49.54.

[62] H. Matsuda, K. Ninomiya, H. Shimoda, and M. Yoshikawa. (2002). "Hepatoprotective principles from the flowers of Tilia argentea (linden): Structure requirements of tiliroside and mechanisms of action". Bioorganic and Medicinal Chemistry. 10 (3): 707-712. 10.1016/S0968-0896(01)00321-2.

[63] F. Jacobs, D. Chaussabel, C. Truyens, V. Leclerq, Y. Carlier, M. Goldman, and B. Vray. (1998). "IL-10 up-regulates nitric oxide (NO) synthesis by lipopolysaccharide (LPS)-activated macrophages: improved control of Trypanosoma cruzi infection". Clinical \& Experimental Immunology. 113 (1): 59 -64. 10.1046/j.1365-2249.1998.00637.x. 